\title{
Framing effects in justice perceptions: Prospect theory and counterfactuals
}

\author{
Deshani B. Ganegoda $^{\mathrm{a}, *}$, Robert Folger ${ }^{\mathrm{b}}$ \\ ${ }^{a}$ Research School of Management, Australian National University, Australia \\ ${ }^{\mathrm{b}}$ Department of Management, College of Business Administration, University of Central Florida, United States
}

\section{A R T I C L E I N F O}

\section{Article history:}

Received 15 April 2013

Accepted 5 October 2014

Accepted by Francesca Gino

\section{Keywords:}

Fairness theory

Prospect theory

Organizational justice

Counterfactuals

\begin{abstract}
A B S T R A C T
The majority of organizational justice research is underscored by the assumption that individuals form justice perceptions based on deliberate processing of information, using various justice judgment criteria. Taking an alternative view, this research examined how individuals form fairness perceptions in less deliberate ways-in particular, based on the way in which a decision outcome is framed. Drawing on prospect theory (Kahneman \& Tversky, 1979), we argued that decision outcomes that are framed in line with prospect theory's predictions would attenuate counterfactual processing because those outcomes are consistent with individuals' biased preferences. Drawing on fairness theory (Folger \& Cropanzano, 1998,2001 ), we argued that lower levels of counterfactual thinking increases the tendency for a decision to seem fair; therefore, framing a decision in a way that is consistent with a pre-existing bias could increase the extent to which it is perceived as fair. We found support for our hypotheses in two experiments.
\end{abstract}

(c) 2014 Elsevier Inc. All rights reserved.

\section{Introduction}

Perceptual illusions are widely shared, yet people are typically not aware their perceptions have been biased; the perceptions seem to reflect reality rather than distortions of it. In the present research, we argue that decision frames affect perceived fairness in a manner similar to how people are affected by perceptual illusions. For example, a line seems longer with endpoint arrows facing inward $(>---<)$ rather than outward $(<--->)$, or gray seems lighter against a black background and darker against a white background. We argue that the way a decision is framed can act similarly in influencing the way individuals evaluate the fairness of that decision.

Why is it important that different ways of framing a decision can alter what gives people the sense of having being treated fairly? In their pioneering work on dispute resolution, Thibaut and Walker (1975) noted how reactions to decisions give this question special significance. They argued that in order to "resolve conflicts in such a way as to bind up the social fabric and encourage the continuation of productive exchange between individuals," it is vital to study "how each of the possible procedural choices is

\footnotetext{
* Corresponding author at: Research School of Management, ANU College of Business and Economics, Australian National University, Canberra, ACT 0200, Australia.

E-mail address: d.ganegoda@anu.edu.au (D.B. Ganegoda).
}

perceived and evaluated by persons subject to the process and by other persons who may at some future time have their rights decided in a similar setting" (p. 67). When people react to choices made by others, perhaps the framing of what options were considered will affect how the decision itself is received; binding up the social fabric could hang in the balance.

Past efforts have made headway on such issues by exploring criteria used to evaluate the fairness of decisions. These include criteria for evaluating characteristics of the decision outcome (distributive justice), the formal properties of approaches to making decisions (procedural justice), and features of the communication process (i.e., interactional justice). For example, research on distributive justice has focused on criteria such as those used to judge alignment between outcomes and contributions (Adams, 1965). Leventhal (1980) proposed criteria for procedural justice such as the availability of appeal mechanisms (cf. Thibaut \& Walker, 1975). Bies and Moag (1986) suggested criteria for interactional justice regarding how certain qualities of communication can foster a sense of fairness about the decision (e.g., politeness, candor).

This criterion-based approach has produced much evidence about the impact of perceived justice ${ }^{1}$ on organizational consequences (see meta-analyses by Cohen-Charash \& Spector, 2001;

\footnotetext{
${ }^{1}$ We use justice and fairness interchangeably, consistent with the organizational justice literature.
} 
Colquitt, Conlon, Wesson, Porter, \& Ng, 2001; Colquitt et al., 2013; Shao, Rupp, Skarlicki, \& Jones, 2013). Nonetheless, that research has emphasized the actual features of decisions-those that can be judged according to fairness relevant criteria (e.g., presence vs. absence of appeal mechanisms)-without sufficient attention to decision frames that might have nothing to do with fairness per se.

Decision frames can bias individuals' preferences in systematic ways. Respondents reading runaway-trolley scenarios (e.g., Foot, 1967; Thomson, 1985), for example, consider whether to sacrifice one life (causing person A to die) in order to save five (persons $\mathrm{B}-\mathrm{F}$, who will die unless the respondent acts so as to kill $\mathrm{A}$ ). The majority decision reverses based on whether the decision is framed as killing or allowing-to-die. Framed as a choice between two trolley tracks, most choose to kill A by throwing a switch that diverts the trolley away from B-F, whereas most allow B-F to die if they can be saved only by pushing A in front of the trolley (e.g., Greene, Sommerville, Nystorm, Darley, \& Cohen, 2001; Hauser, Cushman, Young, Jin, \& Mikhail, 2007; cited by Cushman, 2013). Similarly, what game theorists call "defection" in a Prisoner's Dilemma format seems more hostile when research participants believe they are involved in a "Wall Street game" rather than a "community game" (Liberman, Samuels, \& Ross, 2004).

Our studies provide evidence about justice perceptions as a function of framing effects, drawing on fairness theory (Folger \& Cropanzano, 1998, 2001) and prospect theory (Kahneman \& Tversky, 1979). The latter provides another framing paradigm in which the choice between two options reverses. The former theory predicts that the perceived fairness of a decision will differ depending on the salience of an unchosen option as a counterfactual alternative to the actual choice. Based on prospect theory, we argue that a decision framed congruently with prospect theory's predictions will attenuate counterfactual processing because such a framing will bias an individual's preference toward that decision, and reduce the individual's consideration of alternative options (counterfactuals). Based on fairness theory, we argue that the less a decision triggers counterfactual thinking, the greater the tendency for the decision to seem fair. Thus, we expect a decision that is consistent with the bias articulated in prospect theory to be perceived as fairer than a decision that is inconsistent with prospect theory, when the outcomes, procedures and interactional aspects of the decision are held constant.

The present research contributes to the organizational justice literature in several ways. First, we examine reactions to decisions that are framed consistent with a cognitive bias of those who are evaluating them, which is different from evaluating a decision based on a set of fixed criteria-such as equity or procedural justice rules. The effect of framing goes beyond any specific feature of the decision. Therefore, this research examines a thus-far unexplored antecedent of perceived fairness.

Second, we examine the way in which decision frames affect the fairness evaluation process. Drawing on fairness theory (Folger \& Cropanzano, 1998, 2001), we examine how decision frames influence individuals' counterfactual thinking. Although previous studies have examined the effects of decision frames on individuals' evaluations of decisions (e.g., Gamliel \& Peer, 2010; Kahneman, Knetsch, \& Thaler, 1986, 1994), no study to date has examined counterfactual thinking as an underlying mediating mechanism of framing effects in relation to perceptions of fairness. In explaining the fairness evaluation process, the integration of prospect theory's framing effects and fairness theory's notion of counterfactual thinking is a unique contribution of the present study.

Overall, the present research addresses conceptual links between organizational justice and the literature on judgment and decision-making (JDM). As Highhouse (2001) noted, although the domain of JDM contains relevant theoretical and empirical findings that could potentially benefit areas of organizational behavior and industrial and organizational psychology, there is a serious lack of integration with those two fields. Recognizing this gap, Dalal et al. (2010), recently called for research that integrates theoretical insights from the JDM literature with other management fields. The theoretical confluence presented in this paper is a step in that direction. Next we discuss the conceptual grounds for making predictions.

\section{Fairness theory and counterfactual thinking}

Counterfactuals can be defined as "mental representations of alternatives to the past" (Roese, 1997, p. 133). Counterfactual thoughts can result from conscious and elaborative processing of information or through automatic processes without conscious intent (Kahneman, 1995). This second type of counterfactual processing is the most relevant to framing effects examined in the present research (Roese, 1997). A number of factors can trigger counterfactual thinking. These include the negative affect associated with an outcome, the closeness of an actual outcome to an expected outcome, the degree to which an outcome is controllable and the degree to which an outcome is considered as unusual or unexpected (Roese, 1997).

Fairness theory (Folger \& Cropanzano, 1998, 2001) presumes that counterfactuals relevant to accountability influence perceptions of injustice. The perception of an event as unjust occurs when a person holds another party accountable for an action (or inaction) that caused harm. This accountability involves judgments about the following: (a) perceived harm to a decision-outcome recipient, (b) conduct over which a decision maker has discretionary control, and (c) a decision-maker's moral transgression (discretion exercised in an improper manner). Judgments regarding those elements imply counterfactual scenarios (imaginable alternatives to actual events, processed consciously or below the level of awareness) that make actual events seem unfair by contrast with "if only..." alternatives.

Comparisons between actual events and their associated counterfactual scenarios (the most easily imaginable) will affect fairness perceptions and related reactions to a decision. The relevant counterfactuals involve contrastive alternative scenarios regarding what the outcomes would have felt like if there had been no harm, along with what a decision maker could have and should have done differently (Folger \& Cropanzano, 2001). A recent series of experiments showed that the extent to which a decision prompted such counterfactuals was associated with the extent of perceived unfairness (Nicklin, Greenbaum, McNall, Folger, \& Williams, 2011). The present research represents an extension beyond fairness theory's counterfactual analysis by taking into account (a) a decision's frame, and (b) the way in which a decision's frame biases preference for that decision and influence counterfactual activation, thereby affecting perceptions of fairness.

\section{Prospect theory}

Putting that line of reasoning to an initial test, we combine the counterfactual orientation of fairness theory (e.g., Folger \& Cropanzano, 2001) with predictions from prospect theory (Kahneman \& Tversky, 1979). Prospect theory explicates how the manner in which a decision is framed will influence decision choice when holding the objective outcomes of choice options constant. In prospect theory, a decision frame refers to "the decision-maker's conception of the acts, outcomes, and contingencies associated with a particular choice" as affected "partly by the formulation of the problem and partly by the norms, habits, and personal characteristics of the decision-maker" (Tversky \& Kahneman, 1981, p. 453). Decision frames can function so that out- 
comes are evaluated as either positive (gain) or negative (loss) deviations from a neutral reference point, typically the status quo.

A person's preference for risky or for cautious choices (risk averse, sure-thing, riskless) depends on whether deviations from the reference point occur in a context framed as involving potential losses vs. one involving potential gains. Specifically, prospect theory posits that the value placed on avoiding loss is thus greater than the value placed on attaining gains; losses loom larger than gains. Because individuals subjectively value loss aversion more than gain attainment, they tend to pursue riskier options for loss aversion purposes than for purposes of gain attainment. Put another way, the framing of a decision in terms of gains will make risk-aversion the dominant preference, whereas loss-framed decision contexts will make risk-seeing the dominant preference. This framing effect has been replicated in risk management (Tversky \& Kahneman, 1981), organizational strategy (Schmidt, Starmer, \& Sugden, 2008), economics (Fiegenbaum \& Thomas, 1988), accounting (List, 2004; Plott \& Zeiler, 2007), marketing (Grinblatt \& Han, 2005), neuroscience (Maheswaran \& Meyers-Levy, 1990; Thaler, 1985) and behavioral ethics (Boorman \& Sallet, 2009; Trepel, Fox, \& Poldrack, 2005).

In the present research, we link prospect theory's predictions with the predictions of fairness theory. Specifically, we argue that decision recipients will perceive a decision as fairer, regardless of the outcome, when the decision choice and the frame in which the choice is communicated are consistent with the cognitive bias identified by prospect theory. Applied to a business situation, this rationale suggests that a manager who chooses a risky option might seem fairer to affected parties (or neutral observers) compared with a manager who chooses a riskless option, even though the outcomes and procedures of the two decisions might be similar-provided that the framing of the decision is loss oriented in the eyes of decisionevaluators (affected or third parties). The manager who chooses the risky option in this context acts in the way that seems normal and reasonable because it coincides with the cognitive bias of the decision-evaluators. Therefore, it will be that much harder to generate counterfactual thoughts about how the decision might have been made differently, which in turn will tend to make the decision seem fair. By the same reasoning, a riskless (sure-thing) choice will seem fairer when the decision is framed in terms of gains.

Given the theoretical and empirical research on prospect theory, we expect higher ratings of the chosen option's perceived fairness when a risky decision is made for the purpose of loss aversion rather than gain attainment, and when a riskless decision is made for the purpose of gain attainment rather than loss aversion. It is important to note that we expect this variation in justice perceptions to occur when traditional justice criteria relating to the decision and objective outcomes of the decision are held constant. That is, we expect fairness perceptions to vary solely as a function of the way in which the decision context is framed. Based on this reasoning, we offer the following hypothesis:

Hypothesis 1. A risky choice will be perceived as fairer if it is communicated in a loss frame as compared to a gain frame. In contrast, a riskless choice will be perceived as fairer if it is communicated in a gain frame as compared to a loss frame.

In line with the hypothesis stated above, we expect individuals to engage in less counterfactual thinking when a decision is framed in a manner consistent with the cognitive biases articulated in the prospect theory than when it is not. Furthermore, in line with fairness theory, we expect that counterfactual thinking will have a negative relationship with fairness perceptions. Therefore, we expect the effect of the two-way interaction between frame and risk on perceived fairness (implied by Hypothesis 1) to be mediated by the extent to which individuals generate counterfactuals regarding a decision. Based on this line of reasoning, we propose the following hypothesis:
Hypothesis 2. The way a decision is framed will affect whether the choice associated with it triggers more or fewer counterfactual alternatives. Specifically, a risky choice that is communicated with a loss frame and a riskless choice communicated with a gain frame will generate fewer counterfactuals than a risky choice communicated with a gain frame or a riskless choice communicated in a loss-frame. The relationship between counterfactual generation and perceived fairness will be negative.

Moreover, we expect these relationships to occur when traditional justice criteria relating to the decision and objective outcomes of the decision are held constant.

\section{Overview of experiments}

We tested our hypotheses in two experiments. In the first experiment, we adapted Tversky and Kahneman's (1981) Asian Disease Problem to represent a resource allocation situation in a university to increase the relevancy of the scenario to our participants, who were business students. This experiment tested our Hypothesis 1, which suggests that the way a decision maker frames a choice will affect how individuals evaluate the fairness of the outcomes that result from that choice. Specifically, a choice that is framed consistently with prospect theory will be perceived as fairer than a choice that is framed inconsistently with prospect theory. In order to test our hypothesis, we changed the role of participants from the original Asian Disease Problem (and our adaptation of it), which requires participants to be in the role of the decision maker and instead required them to be decision-outcome recipients. We assessed our dependent variable-perceived decision fairness-by measuring outcome, procedural, and informational justice.

In the second experiment, we used Bazerman's (1983) adaptation of Tversky and Kahneman's (1981) Asian Disease Problem as an organizational layoff situation. We chose Bazerman's adaptation to increase the relevancy of the scenario to our participants, who were working adults. The second experiment was designed to replicate the results of the first experiment using a measure of overall fairness and to test the mediation process of counterfactual thinking, as stated in Hypothesis 2. In addition to the perceived fairness regarding the decision, we also assessed the decision outcome recipient's acceptance of the decision and engagement with the organization in the second experiment.

Note that we held constant various objective aspects of the announced decision that ordinarily might influence fairness perceptions (e.g., outcomes relative to inputs, presence or absence of voice, thoroughness of explanation) across all conditions in both experiments. Thus, if fairness is not influenced by decision framing, in the manner we have hypothesized, the experimental conditions should not differ in fairness perceptions. If our hypotheses are supported, however, we will have obtained the expected variations in our justice measures even though we did not manipulate any objective characteristics that the extant literature has shown to influence perceived justice. Because meta-analytic findings suggest that prospect theory's framing effects ranges between small to medium in size (Kühberger, 1998), we planned to include approximately 40 participants per condition in our experimental studies to ensure sufficient power, as per Maxwell's (2004) guidelines.

\section{Experiment 1}

\section{Pilot study}

For Experiment 1, we created a version of the Asian Disease problem that involved a resource allocation decision in a university setting. Prior to using the scenarios in our main study (in which participants were decision evaluators), we conducted a pilot study 
to test whether our scenario would produce the reflection effect consistent with prospect theory when participants are asked to take on the role of decision-makers. The study employed a single factor (gain-frame vs. loss-frame) between-participant design. The dependent variable of the study was a participant's choice between a risky option (Option 1) and a riskless option (Option 2).

\section{Procedure}

We employed a 2 (frame: gain vs. loss) $\times 2$ (solution's riskiness: risky vs. riskless) between-participants design. The dependent variable was perceived justice regarding the decision. Fifty-five senior business students (32 male and 23 female) from a university in Southeastern United States participated in this study in exchange for partial course credit. All participants who agreed to take part in the study were sent an email with a web link that led to the scenario. The survey website randomly allocated approximately an equal number of participants to gain- and loss-frame conditions.

The scenario involved a professor who had promised a group of 120 undergraduate business students in three separate lab sections he would pay them $\$ 5$ in exchange for completing a short survey. The participants were told that at the time the professor made the announcement about the $\$ 5$ monetary incentive to the students, he was fairly certain that he could obtain his department's research funds to pay all the students that he invited to take part in the survey. Due to a budget constraint that was implemented after he made the announcement, however, the professor found himself in a situation where he did not have sufficient funds to pay all the students from the three lab sections participating in the survey.

Subsequently, participants read the following: "Working with the department's administrative staff, the professor figured that there were two options available to him in terms of handling the issue concerning the monetary incentive." Gain frame: "Option 1 allowed him to use a research grant that is currently available to him for paying students, and definitely pay one lab session and all of its students. Alternatively, Option 2 allowed him to refuse the current research grant and appeal for a bigger grant from the College of Business Administration (he was not allowed to have the current grant and also appeal for a bigger grant). If he appealed and got the bigger grant, he would have sufficient money to pay for all the students. Given that two other departments were also applying for the same money, however, if he chose Option 2, he would only have had a 1/3 probability of getting the grant and paying all three lab sections, and a $2 / 3$ probability of paying no one at all." Loss frame: "Option 1 allowed him to use a research grant that is currently available to him for paying students, but because it was such a small grant, he definitely would not have been able to pay students of two lab sections. Alternatively, Option 2 allowed him to refuse the current department grant and appeal for a bigger grant from the College of Business Administration. Given that two other departments were also applying for the same money, however, if he chose Option 2, he would only have had a 1/3 probability of getting the grant and not disappointing any student, and a 2/3 probability of disappointing all students."

After reading the scenario, participants were asked: "If you were in the professor's position which option would you have chosen?" The choices were "Option 1" or "Option 2."

\section{Results}

The results showed that $77 \%$ of the participants chose Option 1 and $23 \%$ chose Option 2 when presented with a gain-frame. In contrast, $14 \%$ of the participants chose Option 1 and $86 \%$ chose Option 2 when presented with a loss-frame. The findings suggested our scenarios were able to capture the framing effect articulated in prospect theory. Therefore, we used the same scenario as the basis for our laboratory experiment.
Main study

\section{Participants}

One hundred and fifty-two senior business students (80 males) from a large state university participated in this study in exchange for partial course credit. The majority of participants (73\%) were employed full-time or part-time at the time of the survey and reported to have spent an average of $2.38(S D=1.56)$ years in their present job.

\section{Procedure}

All participants were invited to take part in a short online survey in exchange for 5 points extra credit and a $\$ 5$ monetary incentive. The survey was part of a data collection program for a separate and an unrelated study. At the end of the survey, participants were randomly allocated to loss frame or gain frame conditions. Participants were given the scenarios tested in the pilot study. However, rather than ask them what option they would have chosen in situation, they were told that after careful consideration the professor chose Option 1 (riskless condition) or Option 2 (risky condition).

\section{Measures}

The dependent variable, perceived fairness of the decision, was measured with 6 items relating to outcomes, procedures, and information. Outcome fairness was measured with the following two items: "Whether or not you get paid, do you think that the decision about the monetary incentive was fair?" and "Considering the projected outcomes for Options 1 and 2, do you think the researcher made a justifiable decision?" Procedural justice was measured with the following item (Konovsky, Folger, \& Cropanzano, 1987): “How fair were the practices the researcher followed in reaching a decision about the monetary incentive?" Informational justice was measured using three items adapted from Colquitt's (2001) measure of organizational justice. A sample item from the informational justice scale was "Do you think the researcher's explanation regarding the monetary incentive was reasonable?" We calculated a composite score of justice (Cronbach's alpha $=.80$ ) because of three reasons: (1) we did not have separate predictions for different types of justice, (2) justice subsets were all positively correlated (correlations ranged from .48 to .59), and (3) we found a similar pattern of results across the three different types of justice when each dimension was assessed individually. ${ }^{2}$ All items were rated on a 5-point Likert type response format ranging from 1, "not at all," to 5, "to a very large extent."

At the end of the experiment, participants completed a funneled debriefing questionnaire, which checked for awareness or suspicion of the purpose of the experiment. Three participants reported suspicion regarding the scenario and were excluded from the final analyses. All participants were debriefed after the experiment and were paid the $\$ 5$ that was initially promised.

\section{Results}

We conducted an ANOVA to test our Hypothesis 1 . The results revealed a significant two-way interaction between decision frame and the solution's riskiness, $F(1,148)=24.53, p<.001$, eta squared $=.15$. As shown in Fig. 1 , the pattern of the interaction was as predicted. Consistent with Hypothesis 1, the results from

\footnotetext{
${ }^{2}$ We also conducted separate ANOVA analyses for each subset of justice. Results showed a significant interaction effect between decision frame and the solution's riskiness for outcome fairness, $F(1,145)=11.67, p<.001$, partial eta squared $=.07$; procedural justice, $F(1,145)=14.99, p<.001$, partial eta squared $=.09$; and informational justice, $F(1,145)=22.42, p<.001$, partial eta squared $=.13$. The patterns of al the interactions were similar and consistent with Hypothesis 1.
} 


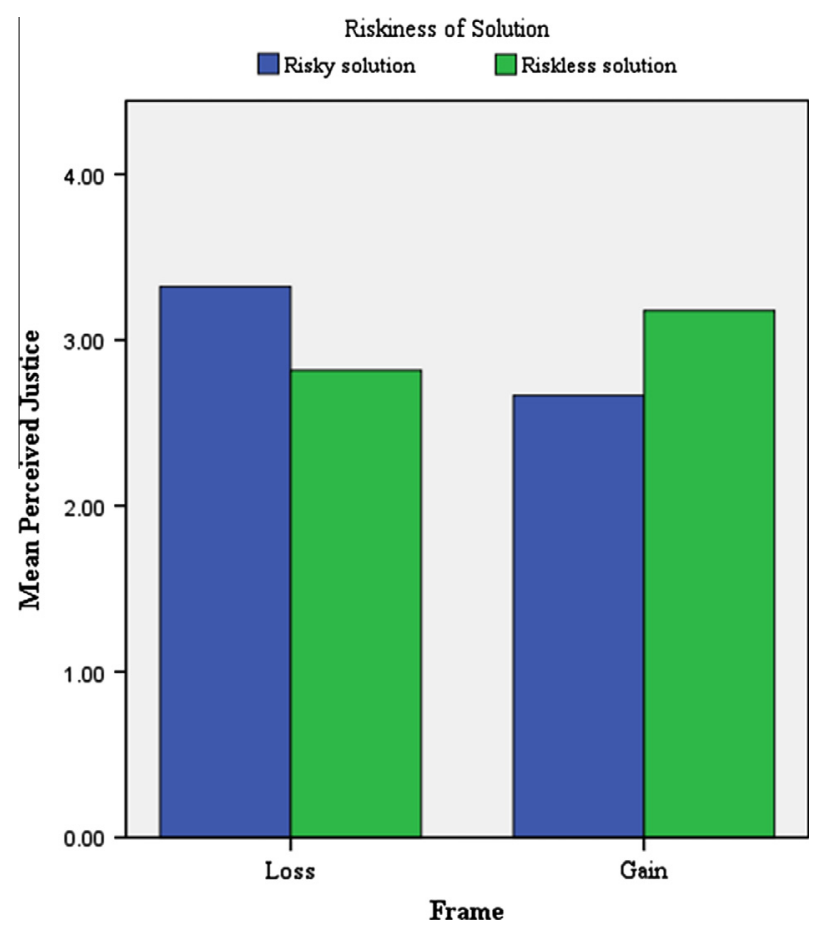

Fig. 1. Perceived justice as a function of decision frame and solution riskiness (Experiment 1).

simple-effects tests showed that participants in the loss-framed condition perceived the riskier option (Mean $=3.32, S D=0.53$ ) to be significantly fairer than the riskless option (Mean $=2.82$, $S D=0.56), F(1,145)=14.32, p<.001$, and participants in the gainframed condition perceived the riskless option (Mean $=3.18$, $S D=0.73)$ to be significantly fairer than the riskier option $($ Mean $=2.67, S D=0.68), F(1,145)=10.77, p<.01$. $^{3}$

\section{Discussion}

The purpose of Experiment 1 was to test whether the way in which a decision's context was framed would influence an individual's perceived fairness regarding the decision. Our results revealed that in the loss-framed context, participants who were told that the decision-maker had chosen a risky solution gave significantly higher fairness ratings than did the participants who were told that the decision-maker had chosen a riskless solution. In the gainframed context, however, participants who were told that the decision-maker had chosen a riskless solution gave significantly higher ratings that did the participants who were told that the decisionmaker had chosen a risky solution. Those results are consistent with Hypothesis 1. Importantly, we found this effect irrespective of the favorability of the outcome, and across conditions that did not differ in terms of the organizational literature's known determinants of perceived justice. Overall, the results of Experiment 1 suggest that participants' perceived fairness was influenced by the extent to which the decision maker's choice was consistent with the frame, as articulated in prospect theory. Decision choices that were consistent with the frame were perceived as fairer than decisions that were inconsistent with it.

\footnotetext{
${ }^{3}$ We also included a condition with positive outcome favorability. We found a main effect of outcome favorability on fairness perceptions, but we did not find a significant three-way interaction among outcome favorability, framing, and decision risk. This suggests that the interaction between frame and decision risk did not differ based on favorability of the outcome. Outcome favorability was not used as a factor in the final analysis as it did not interact with the other two factors.
}

\section{Experiment 2}

The main purpose of Experiment 2 was to examine whether framing a decision choice consistent with the bias stated in prospect theory would reduce counterfactual thinking as suggested in Hypothesis 2, and whether counterfactual thinking would, in turn, affect the perceived fairness of the decision.

\section{Pilot study}

Before having participants in the main study take the role of decision-evaluators (outcome recipients affected by the decision), we conducted a pilot study to establish that the scenarios used in the main study would indeed produce the prospect-theory's framing effect (gain/loss framing effect) when the participants were decision-makers. Based on prospect theory, we predicted that those who were exposed to a gain-frame would prefer the riskless option (Option 1) and those who were exposed to a loss-frame would prefer the risky option (Option 2). The study employed a single factor (gain-frame vs. loss-frame) between-participant design. The dependent variable was the participants' choice between Option 1 and Option 2.

\section{Procedure}

Seventy senior business students (32 males) from a university in Southeastern United States participated in this study in exchange for partial course credit. All participants were sent an email with a web link that led to the scenario. Participants were randomly allocated to gain- and loss-frames ( $n=35$ in each condition). All participants first read the following scenario:

"Due to the recent downturn in the economy, a car manufacturing company is faced with a crisis that has affected three of its plants, each of which employs 2000 people. Last Monday, the senior manager of the company visited one of the plants and presented the following information in an employees' meeting. 'I believe most of you are aware that our company is going through a very difficult economic crisis. Working with the accountants, we figured that there were two options of what to do to survive through this economic crisis. Under Option 1, we can definitely save one plant and its $2000 \mathrm{jobs}$ (gain frame)/ Under Option 1, two of our plants and 4000 jobs will definitely be lost (loss frame). Alternatively, under Option 2, we have a 1/3 probability of saving all three plants and all 6000 jobs, but we have a 2/3 probability of saving no plants and no jobs (gain frame)/ Alternatively, under Option 2, we have a 1/3 probability of losing no plants and no jobs, but we have a 2/3 probability of losing all three plants and all 6000 jobs (loss frame)."

After reading the scenario, participants were asked: "Which option would you select if you are the senior manager of the company?" The choices were "Option 1" and "Option 2."

\section{Results}

The results showed that $79 \%$ of the participants chose Option 1 and $21 \%$ chose Option 2 when presented with a gain-frame. In contrast, $11 \%$ of the participants chose Option 1 and $89 \%$ chose Option 2 when presented with a loss-frame. This suggests that our framing manipulation had the desired effect.

\section{Main study}

\section{Participants}

One hundred and forty-five (59 male) individuals participated in this study. All participants were working adults who were recruited via Amazon's Mechanical Turk (MTurk). Participants reported to have spent an average of $3.45(S D=4.06)$ years in their present job. 


\section{Procedure}

A 2 (frame: gain vs. loss) $\times 2$ (option choice: risky vs. riskless) between-participants design was employed. The dependent variables were perceived justice regarding the decision, overall support for the decision, and a participant's engagement with the company. All participants were informed that the scenario they were given actually occurred in a real company and that their task was to assume the role of an employee and read the scenario. Subsequently, participants were given the scenarios tested in the pilot study, but instead of asking the participants what they would do, they were told that after careful consideration, the management chose Option 1 (riskless choice)/Option 2 (risky choice).

\section{Measures}

The focal dependent variable, the perceived justice regarding the decision, was measured by adapting Ambrose and Schminke's (2009) measure of overall justice. A sample item from this measure is: "For the most part, the way the manager acted was fair." In addition to measuring perceived justice as the dependent variable, we also collected two other measures. Specifically, we measured the extent to which a participant would accept the company's decision using the following two items (Skitka \& Mullen, 2002): "Do you think the company made the right decision?" and "Are you for an attempt to overturn this decision?" We also collected a behavioral measure, a participant's engagement with the company, by asking the following: "The company described above scenario is running a number of focus groups to improve its marketing strategy. Please indicate below if you would like to be part of one of their focus groups." Participants were asked to click on a web link to sign up for the focus groups.

In order to solicit participants' counterfactual thinking, we asked participants to list any "what if" or "if only" thoughts that came to their minds when they read the scenario. This approach has been used in previous studies to measure counterfactual thinking (e.g., Kray \& Galinsky, 2003; Nicklin et al., 2011). Two independent coders identified the number of thoughts listed by participants that were counterfactual in nature. The reliability for counterfactual thoughts was high (alpha $=.91$ ), and therefore the ratings of the two coders were averaged. Additionally, we also coded the responses based on whether a participant referred to the alternative option as a better solution compared to the one that was selected by the decision maker (reference to the alternative option as a better solution $=1$, absence of any reference to the alternative solution $=0$ ).

\section{Results}

Table 1 gives the descriptive statistics, correlations and reliability statistics of the study's measures. We hypothesized that a risky decision option would be perceived as fairer if it is communicated with a loss frame as compared to a gain frame, whereas a riskless option would be perceived as fairer if it communicated in a gain frame as compared to a loss frame (Hypothesis 1). Further, we expected an individual's counterfactual thinking would mediate the effect of the two-way interaction on perceived fairness (Hypothesis 2).

To test Hypothesis 1, we first conducted a multivariate analysis of variance (MANOVA) with perceived justice and decision support as the dependent variables, and decision frame and solution riskiness as between-participant factors. Consistent with Hypothesis 1 , the MANOVA indicated a significant two-way interaction between decision frame and the solution riskiness $[F(2,140)=6.46, p<.01$, Wilk's Lambda $=.92$, partial eta squared $=.09]$.

The results of univariate ANOVAs yielded significant interaction effects between decision frame and solution riskiness for perceived justice, $F(1,144)=7.68, p<.01$, partial eta squared $=.05$ and deci- sion acceptance, $F(1,144)=11.59, p<.01$, partial eta squared $=.08$. The patterns of all the interactions were similar to and consistent with those found in Experiment 1. Results from simple-effects tests were consistent with Hypothesis 1. Participants in the loss-framed conditions who read that the decision-maker had chosen the risky solution gave significantly higher fairness ratings (Mean $=4.77$, $S D=1.05$ ) than the participants who read that the decision-maker had chosen the riskless solution (Mean $=4.21, S D=0.92$ ), $F(1,141)=4.57, p<.05$. Similarly, the former were more willing to accept the risky solution (Mean $=4.76, S D=1.14$ ) than the latter were to accept the riskless solution (Mean $=4.13, S D=1.07$ ), $F(1,141)=4.20, p<.05$. Likewise, participants in the gain-frame conditions who read that the decision-maker had chosen the riskless solution gave higher fairness ratings (Mean $=4.56, S D=1.12$ ) than participants who read that the decision-maker had chosen the risky solution, although the difference was only marginally significant $($ Mean $=4.09, S D=1.36), F(1,141)=3.18, p=.07$. Participants in the gain-frame condition were also significantly more willing to accept the riskless solution (Mean $=4.50, S D=1.26)$ compared to the risky solution (Mean $=3.64, \quad S D=1.72$ ), $F(1,141)=7.64, p<.01$ (see Figs. 2 and 3 ).

We conducted a binary logistic regression to determine whether the participants who were in the prospect theory compatible conditions chose to participate in the company's focus groups more than the participants who were in the prospect theory incompatible conditions. A single dichotomous predictor was used to represent the compatibility of the decision frame and risk, with the two prospect theory compatible conditions coded as 1 and the two incompatible conditions as 0 . The dependent variable was coded as 1 to represent participation and 0 to represent non-participation in the focus group. Consistent with Hypothesis 1, the results indicated that more participants in prospect theory compatible conditions (66\%) signed up for the focus groups compared to those who were in the prospect theory incompatible conditions (49\%), $b=.70, S E=.34, p<.05$.

In the final set of analyses, we tested the mediation effect of counterfactual thinking as suggested in Hypothesis 2. Results of a linear regression suggested a significant negative relationship between prospect theory consistent conditions and the number of counterfactuals generated, $b=-.43, S E=.20, p<.05$. Furthermore, results of a binary logistic regression revealed that those who were in prospect theory consistent conditions referred to the alternative option as a better option significantly less $(27 \%)$ than those who were in the prospect theory inconsistent conditions (45\%), $b=-.80, S E=.35, p<.05$.

Following Preacher and Hayes's (2008) method, the indirect effect of counterfactual thoughts was examined by calculating the bias-corrected 95\% confidence intervals ( $\mathrm{CI}$ ) of the estimate, using 5000 bootstrap re-samples. As shown in Fig. 4, the indirect effect of bias confirmation via counterfactual thoughts on perceived justice was significant. Thus Hypothesis 2 was supported. The direct effect, however, was significant even after accounting for the mediation effect of counterfactual thinking; thus indicating that counterfactual thinking was only a partial mediator.

\section{Discussion}

In Experiment 2, we sought to replicate the findings of Experiment 1 using a measure of overall justice and a behavioral measure that indicated engagement with the decision-maker (i.e., the company). Furthermore, we tested the mediating role of counterfactual thinking, suggested in Hypothesis 2. Overall, the findings of Experiment 2 corroborated the results of our previous experiment. We found that in addition to perceptions of decision fairness, the extent to which the decision was consistent with the prospect theory bias influenced individuals' decision acceptance and their 
Table 1

Experiment 2: Means, standard deviations, and correlations.

\begin{tabular}{|c|c|c|c|c|c|c|}
\hline Variable & Mean & $S D$ & 1 & 2 & 3 & 4 \\
\hline 1. Perceived justice & 4.41 & 1.14 & $(.73)$ & & & \\
\hline 2. Decision acceptance & 4.27 & 1.38 & $.55^{* *}$ & $(.67)$ & & \\
\hline 3. Future engagement & 0.58 & 0.50 & $.38^{* *}$ & $.18^{*}$ & - & \\
\hline 4. Counterfactual thinking (count) & 2.21 & 1.25 & $-.21^{*}$ & $-.17^{*}$ & -.02 & $(.91)$ \\
\hline 5. Counterfactual thinking (binary) & 0.36 & 0.48 & $-.18^{*}$ & $-.31^{* *}$ & -.00 & $.31^{* *}$ \\
\hline
\end{tabular}

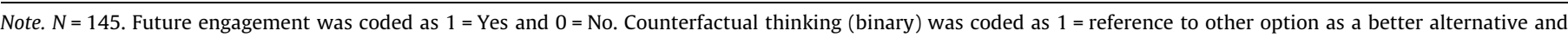
$0=$ no reference to other option. Alpha reliabilities (in parentheses) appear on the diagonal.

${ }^{*} p<.05$.

** $p<.01$.

engagement with the company. The results also revealed that participants' counterfactual thinking partially mediated the effect of a match between decision frame and solution riskiness on perceived justice.

\section{General discussion}

Drawing on prospect theory (Tversky \& Kahneman, 1981) and fairness theory (Folger \& Cropanzano, 1998, 2001), we argued that decision choices that are consistent with the framing effect articulated in prospect theory would result in lower levels of counterfactual thinking and higher levels of perceived fairness regarding the decision. The results of two experiments supported our hypotheses. Specifically, we found that decision-outcome recipients viewed decision choices that were consistent with the framing effects articulated in prospect theory to be fairer than those that were not. Our results showed that counterfactual thinking mediated this effect.

\section{Theoretical contribution}

First, the present research brings a fresh perspective to issues regarding fairness as a dependent variable. To date, scholars have addressed that topic by classifying the fairness of the chosen behavior (the dependent variable) on an a priori basis. The choice to provide voice allows for an a priori classification of voice as fair and no-voice as unfair, for example, and the corresponding research would seek to find the antecedents influencing that choice. Cognitive biases introduced by decision frames, on the other hand, more directly target fairness in the eye of the beholder. As mentioned before, fairness considerations subject to framing effects are like perceptual illusions about lines that seem to differ even though they have the same length: 200 saved out of 600 is no better or worse, no more just or unjust, than 400 lost out of 600 . Identifying the antecedents that determine whether a decision-maker acts in a "fair" manner thus becomes, from this new perspective, a matter of using theory to discover how and when contextual features of a decision, such as a decision's frame, will bias the decision-maker: If affected parties or third-party observers share the same bias (just as some perceptual illusions affect everyone the same way), it will be that much harder to imagine the decision having been made differently, which will tend to make the decision seem fair.

Second, the findings of this study highlight the role of cognitive biases as implicit mental processes of individuals' fairness perceptions. Using measures that relate to specific justice dimensions (Experiment 1) as well as overall justice (Experiment 2), we were able to show that perceptions of justice are sometimes influenced by decision frames in ways that individuals are not fully aware of, and for reasons that they might not be able to explain. In our first experiment, for example, we were able to find significant variance in perceptions of justice in line with our predictions even though we did not vary any justice related information across conditions. Given that we found variance in participants' perceptions of justice without changing any objective features of the decision, these results suggest that perceptions of justice can be formed in a relatively "rapid" and "automatic" manner as a result of inherent cognitive biases (Kahneman, 2003), as opposed to a more deliberative processing of information. Overall, our findings add to the small but growing literature on factors other than the traditional justice criteria (e.g., equity, equality, need, voice, procedural consistency, respectful treatment) that affect individuals' fairness perceptions (Kwong \& Wong, 2014; Li et al., 2011).

Third, the present research constitutes the first linkage of this type that combines fairness theory with prospect theory as the basis for a prediction regarding perceived fairness. A number of previous studies have examined how decision frames influence perceptions of fairness (e.g., Gamliel \& Peer, 2010; Kahneman et al., 1986, 1994). Those studies, however, focused on the way in which framing affects the evaluation of fairness concerning a single outcome. In contrast, the present research focused on the specific context of a delivered message in which the decisionmaker explicitly referred to having actively considered different ways of approaching an issue that would impact the decision evaluator. This difference is very relevant to actual situations in which choices are known to a decision maker and not necessarily to the

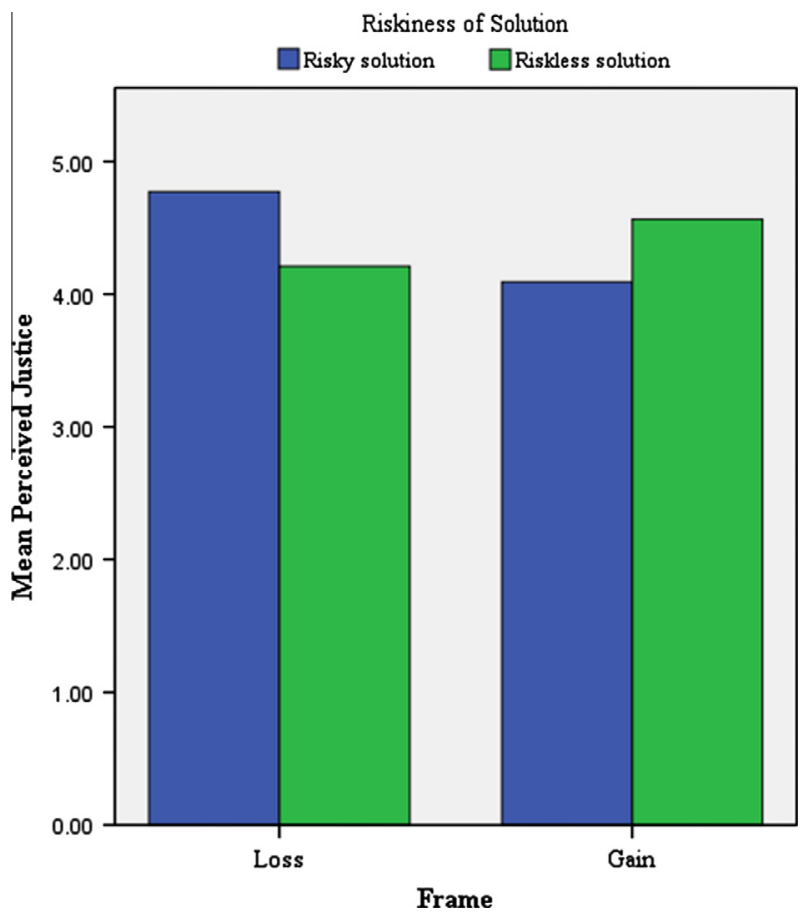

Fig. 2. Perceived justice as a function of decision frame and solution riskiness (Experiment 2). 


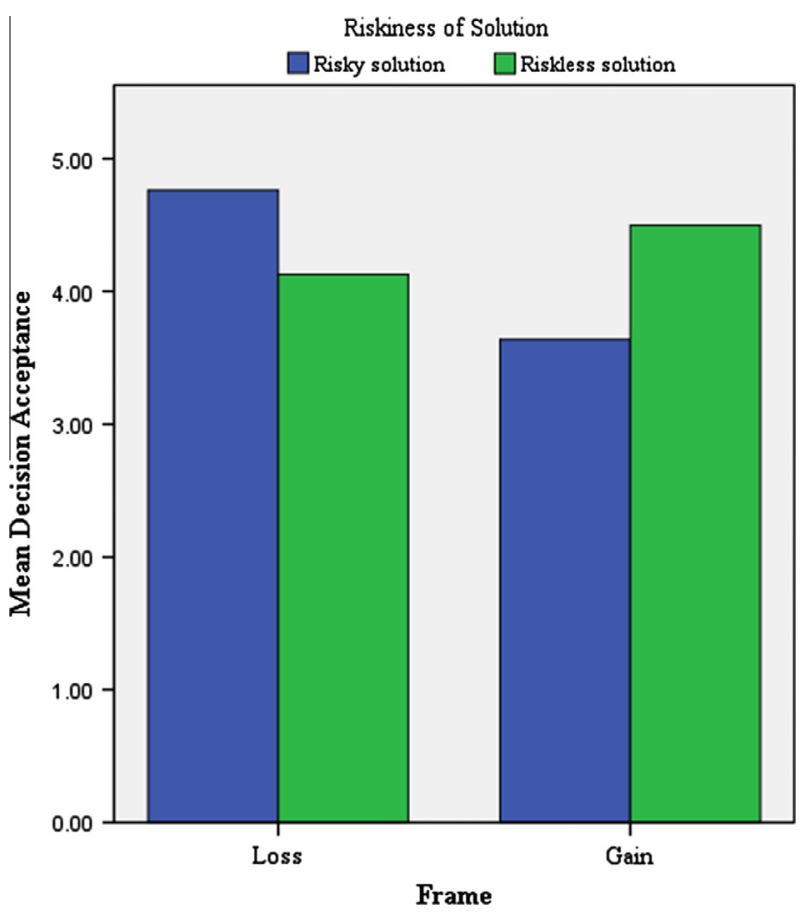

Fig. 3. Decision acceptance as a function of decision frame and solution riskiness (Experiment 2).

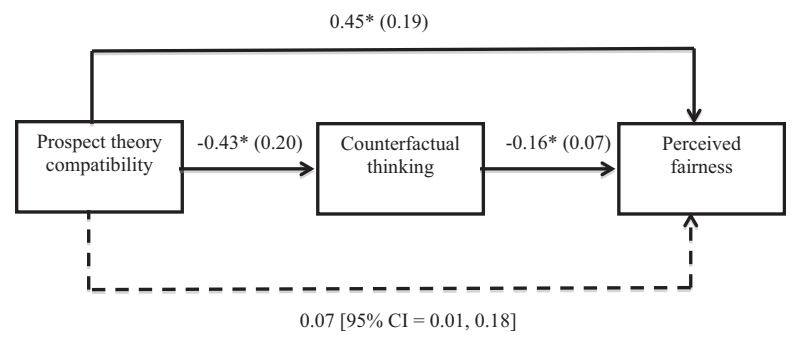

Fig. 4. Mediation results for counterfactual thinking (Experiment 2). Note. $N=145$. Prospect theory compatibility was coded as $0=$ incompatible and $1=$ compatible. Reported estimates are unstandardized regression coefficients. Standard deviations are given in parenthesis. The dotted line indicates the indirect effect of prospect theory compatibility on perceived fairness via counterfactual thinking. The $95 \%$ confidence interval for the indirect effect is given in square brackets. These values are obtained by the bias-corrected bootstrap with 5000 re-samples. ${ }^{*} p<.05$.

evaluator. Our findings reveal how an aspect of revealing the unchosen options can influence perceptions of fairness through the counterfactual contrasts individuals make in evaluating the fairness of the decision. This is a unique contribution of the present study.

In particular the present study should be distinguished from a previous study by Brockner, Wiesenfeld, and Martin (1995) that took into account the propositions of prospect theory in the context of organizational justice. That study demonstrated how decision framing could affect the way in which perceived outcome favorability interacts with procedural justice to influence employees' reactions to decisions. Our merging of prospect theory and fairness theory, however, differs in scope. Our fundamental conceptualization speaks to the broader intertwining of the literatures on behavioral decision-making and organizational justice, and thus it has the potential to extend beyond a narrower focus on specific theories. The notion of a decision confirming an evaluator's preexisting bias is a broader concept; we merely drew from prospect theory because it provides one way of operationalizing that broader concept. Norm theory (Kahneman \& Miller, 1986), reference-dependent fairness (see Kahneman, 2011), and Parducci's (1965) range-frequency theory indicate potential sources of biases to consider when testing whether our findings might generalize to other cognitive biases. Each of these theories presents predictions about ways in which individuals might develop preferences for certain outcomes over others, and hence might have implications for evaluations of those outcomes, such as their fairness.

Our focus on the "here's what wasn't chosen" delivery of information about a decision goes beyond what someone looking through the current organizational justice literature might find regarding how social accounts affect fairness perceptions when decisions are communicated. A discussion by Bies (1987) identified referential accounts, which is the category most relevant to the studies we conducted. There are at least three major differences. First, Bies (1987) was addressing the tactical use of accounts as part of what he called the "management of moral outrage" (p. 289). Counterfactuals, on the other hand, do not have to result from a deliberate attempt by decision-makers to affect fairness perceptions; in fact, such perceptions can be affected by the decision-evaluator's mere awareness that some alternative choice existed-or by anything that causes such an alternative to become part of the mental processing of the event, whether in conscious awareness as an actual alternative, or below the level of awareness and involving a purely hypothetical alternative (Folger, 1987; Folger \& Cropanzano, 1998). Second, the underlying mechanism of the referential accounts described by Bies (1987) is how a decision can be made to seem better by comparison with a worse one (e.g., justifying the decision as actually more magnanimous than it might have seemed otherwise). The prospect theory basis for the Asian disease results (and hence a basis applicable to our modification), on the other hand, explicitly matches the expected-value outcomes of the two alternatives; the prospects differ in riskiness, not in the favorability of the outcomes to be expected from one option vs. the other, and the decision-maker communicates nothing designed as an attempt to make the unchosen option seem any better or worse than the chosen option. The third difference relates to the second: Rather than a better/worse juxtaposition of outcomes, we drew attention to the nature of a cognitive bias regarding risky and riskless alternatives (choice under uncertainty), how to choose between them, and when such matters would affect fairness perceptions.

Finally, our work extends applications of prospect theory in a distinctive way. Kahneman and Tversky's (1979) prospect theory was proposed as a descriptive theory of decision-making under risk. The focal point of interest in prospect theory, therefore, lies in the decision-maker. In the present investigations, however, we extended the applicability of prospect theory by utilizing it to explain the perceptions and attitudes of decision-outcome recipients and third party observers. In so doing, we demonstrated that the bias toward avoiding losses articulated by Kahneman and Tversky (i.e., losses loom larger than gains) held not only when individuals made decisions, but also when individuals evaluated decisions made by others.

\section{Practical implications}

From a practical perspective, the current findings provide insights into the benefits of framing the decision context, and in particular with regard to the communication of decision outcomes that have varying degrees of associated risks. The results of the present study indicate that as much as the content of the explanations is important, the manner in which the content is presented (framed) is also important in managing employees' reactions.

Second, our results highlight the manner in which pre-disposed cognitive biases affect justice perceptions, especially as they relate 
to decision risk. Although a number of theoretical predictions and empirical research findings have explicated some of the important cognitive processes that underscore justice perceptions (e.g., Li et al., 2011; Nicklin et al., 2011; Spencer \& Rupp, 2009), thus far there has been an absence of research conducted on biases that might influence perceptions of justice in relation to decision risk. The findings of the present study demonstrate that individuals assess the fairness of the decision risk in conjunction with the context in which the decision was made (e.g., in the context of loss aversion or gain attainment), and that when communications depict a choice among options consistent with biases toward those options, perceived fairness is enhanced.

\section{Limitations}

As with all research, these studies have their limitations. The extent to which our findings generalize to the workplace cannot be determined, for example, because neither of the two experiments were conducted in the field. In particular, the outcomes at stake might have been low on personal meaningfulness relative to some of the decisions that affect employees at work (e.g., layoffs, promotions). The nature of our participants in Experiment 2 (i.e., working adults) and our adaptation of the Asian disease problem to represent an organizational layoff situation, however, help to attenuate that possible limitation.

Arguments supporting the generalizability of results such as ours have also found a place in the management literature. Locke (1986), for example, has shown that when the focal subject of interest is a phenomena present in most people (such as cognitive biases in decision making) the external validity of laboratory findings is seldom an issue. Attesting to this, a content analysis of empirical studies revealed that laboratory research using college students "provides as firm a basis for generalization to the population of working people and organizations as does field research" (Dipboye \& Flanagan, 1979, p. 147). Collectively, these and other studies (e.g., Anderson \& Bushman, 1997) provide support for the generalizability of experimental findings to the field in general and to the workplace in particular.

It must be noted that our measure of counterfactual thinking required participants to list counterfactual thoughts that came to their minds while reading the scenario. This approach might have prompted the participants to engage in counterfactual thinking, and thereby influenced the very construct it attempted to measure. Of course, such an influence should have affected all conditions of the study-thus, it could not have necessarily affected the final results. Nonetheless, this was a limitation of our counterfactual measure. Future research should attempt to use more non-obtrusive ways of measuring counterfactual thoughts.

In our attempt to make the laboratory study more realistic to our participants, we did not precisely parallel the terminology we used in the loss-frame and the gain-frame scenarios. As evidenced by the results of our pilot study, this did not prevent us from obtaining the desired framing effects. However, we must note that a set of more parallel scenarios could have provided a stricter test of framing effects in Experiment 1. This concern is somewhat mitigated because we were able to replicate the results of Experiment 1 using far more parallel gain frame and loss frame scenarios in Experiment 2.

\section{Conclusion}

The present research is much more than an instance of assessing fairness perceptions in a situation with Asian disease characteristics, therefore, because we have used it to highlight how such perceptions depend on the frame created when a decision is rendered. We have emphasized that these studies represent the tip of the iceberg as far as such effects are concerned, and that this research serves to provide an illustration of how one kind of link between fairness theory and prospect theory opens the door to further investigations on how implicit biases affect fairness perceptions. Moreover, we have linked these two theories in a way that expands the domain of what the organizational justice literature has treated under such headings as procedural justice and informational justice. The evaluation of the fairness of a decision can be subject to framing effects that do not fall neatly into such categories, therefore we think it is time to "look between the cracks" of those neatly circumscribed categories, especially by capitalizing on the wealth of material in the literature on behavioral decision making (Beach, 1997).

\section{Acknowledgment}

The authors thank Russell Cropanzano for his helpful comments on an earlier version of the manuscript.

\section{References}

Adams, J. S. (1965). Inequity in social exchange. In L. Berkowitz (Ed.). Advances in experimental social psychology (Vol. 2, pp. 267-299). New York: Academic Press. Ambrose, M. L., \& Schminke, M. (2009). The role of overall justice judgments in organizational justice research: A test of mediation. Journal of Applied Psychology, 94, 491-500.

Anderson, C. A., \& Bushman, B. J. (1997). External validity of "trivial" experiments: The case of laboratory aggression. Review of General Psychology, 1, 19-41.

Bazerman, M. H. (1983). Negotiator judgment: A critical look at the rationality assumption. American Behavioral Scientist, 27, 211-228.

Beach, L. R. (1997). The psychology of decision making. London: Sage.

Bies, R. J. (1987). The predicament of injustice: The management of moral outrage. In L. L. Cummings \& B. Staw (Eds.). Research in organizational behavior (Vol. 9, pp. 289-319). Greenwich, CT: JAI Press.

Bies, R. J., \& Moag, J. S. (1986). Interactional justice: Communication criteria of fairness. In R. J. Lewicki, B. H. Sheppard, \& M. H. Bazerman (Eds.). Research on negotiations in organizations (Vol. 1, pp. 43-55). Greenwich, CT: JAI Press.

Boorman, E. D., \& Sallet, J. (2009). Mean-variance or prospect theory? The nature of value representation in the human brain. The Journal of Neuroscience, 29, 7945-7947.

Brockner, J., Wiesenfeld, B. M., \& Martin, C. L. (1995). Decision frame, procedural justice, and survivors' reactions to job layoffs. Organizational Behavior and Human Decision Processes, 63, 59-68.

Cohen-Charash, Y., \& Spector, P. E. (2001). The role of justice in organizations: A meta-analysis. Organizational Behavior and Human Decision Processes, 86, 278-321.

Colquitt, J. A. (2001). On the dimensionality of organizational justice: A construct validation of a measure. Journal of Applied Psychology, 86, 386-400.

Colquitt, J. A., Conlon, D. E., Wesson, M. J., Porter, C. O. L. H., \& Ng, K. Y. (2001). Justice at the millennium: A meta-analytic review of 25 years of organizational justice research. Journal of Applied Psychology, 86, 425-445.

Colquitt, J. A., Scott, B. A., Rodell, J. B., Long, D. M., Zapata, C. P., Conlon, D. E., et al. (2013). Justice at the millennium, a decade later: A meta-analytic test of social exchange and affect-based perspectives. Journal of Applied Psychology, 98, $199-236$.

Cushman, F. (2013). Action, outcome and value: A dual-system framework for morality. Personality and Social Psychology Review, 17, 273-292.

Dalal, R. S., Bonaccio, S., Highhouse, S., Ilgen, D. R., Mohammed, S., \& Slaughter, J. E. (2010). What if industrial-organizational psychology decided to take workplace decisions seriously? Industrial and Organizational Psychology: Perspectives on Science and Practice, 3, 386-405.

Dipboye, R. L., \& Flanagan, M. F. (1979). Research settings in industrial and organizational psychology: Are findings in the field more generalizable than in the laboratory? American Psychologist, 34, 141-150.

Fiegenbaum, A., \& Thomas, H. (1988). Attitudes toward risk and the risk-return paradox: Prospect theory explanations. Academy of Management Journal, 31, 85-106.

Folger, R., \& Cropanzano, R. (1998). Organizational justice and human resource management. Beverly Hills, CA: Sage.

Folger, R., \& Cropanzano, R. (2001). Fairness theory: Justice as accountability. In J. Greenberg \& R. Cropanzano (Eds.), Advances in organizational justice (pp. 1-55). Palo Alto, CA: Stanford University Press.

Folger, R. (1987). Reformulating the preconditions of resentment: A referent cognitions model. In J. C. Masters \& W. P. Smith (Eds.), Social comparison, justice, and relative deprivation: Theoretical, empirical, and policy perspectives (pp. 183-215). Hillsdale, NJ: Lawrence Erlbaum Associates.

Foot, P. (1967). Theories of ethics. London: Oxford University Press. 
Gamliel, E., \& Peer, E. (2010). Attribute framing affects the perceived fairness of health care allocation principles. Judgment and Decision Making, 5, 11-20.

Grinblatt, M., \& Han, B. (2005). Prospect theory, mental accounting, and momentum. Journal of Financial Economics, 78, 311-339.

Highhouse, S. (2001). Judgment and decision-making research: Relevance to industrial and organizational psychology. In N. Anderson, D. S. Ones, H. K. Sinangil, \& C. Viswesvaran (Eds.). Handbook of industrial, work, and organizational psychology (Vol. 2, pp. 314-331). London: Sage.

Kahneman, D. (2003). A perspective on judgment and choice: Mapping bounded rationality. American Psychologist, 58, 697-720.

Kahneman, D. (2011). Thinking, fast and slow. New York: Farrar, Straus, \& Giroux.

Kahneman, D., Knetsch, J. L., \& Thaler, R. H. (1986). Fairness and the assumptions of economics. Journal of Business, 59, 285-300.

Kahneman, D., Knetsch, J. L., \& Thaler, R. (1994). Fairness as a constraint on profit seeking: Entitlements in the market Quasi Rational Economics. New York: Russel Sage, pp. 199-219.

Kahneman, D., \& Miller, D. T. (1986). Norm theory: Comparing reality to its alternatives. Psychological Review, 93, 136-153.

Kahneman, D. (1995). Varieties of counterfactual thinking. In N. J. Roese \& J. M. Olson (Eds.), What might have been: The social psychology of counterfactual thinking (pp. 375-396). Mahwah, NJ: Erlbaum.

Kahneman, D., \& Tversky, A. (1979). Prospect theory: An analysis of decisions under risk. Econometrica, 47, 263-291.

Konovsky, M. A., Folger, R., \& Cropanzano, R. (1987). Relative effects of procedural and distributive justice on employee attitudes. Representative Research in Social Psychology, 17, 15-24.

Kray, L. J., \& Galinsky, A. D. (2003). The debiasing effect of counterfactual mind-sets: Increasing the search for disconfirmatory information in group decisions. Organizational Behavior and Human Decision Processes, 91, 69-81.

Kühberger, A. (1998). The influence of framing on risky decisions: A meta-analysis. Organizational Behavior and Human Decision Processes, 75, 23-55.

Kwong, J. Y. Y., \& Wong, K. F. E. (2014). Fair or not fair? The effects of numerical framing on the perceived justice of outcomes. Journal of Management, 40, $1558-1582$.

Leventhal, G. S. (1980). What should be done with equity theory? New approaches to the study of fairness in social relationships. In K. Gergen, M. Greenberg, \& R. Willis (Eds.), Social exchange: Advances in theory and research (pp. 27-55). New York: Plenum Press.

Li, A., Evans, J., Christian, M. S., Gilliland, S., Kausal, E. E., \& Stein, J. H. (2011). The effects of managerial regulatory fit priming on reactions to explanations. Organizational Behavior and Human Decision Processes, 115, 268-282.

Liberman, V., Samuels, S. M., \& Ross, L. (2004). The name of the game: Predictive power of reputations versus situational labels in determining Prisoner's Dilemma game moves. Personality and Social Psychology Bulletin, 30, 1175-1185.
List, J. A. (2004). Neoclassical theory versus prospect theory: Evidence from the marketplace. Econometrica, 72, 615-625.

Locke, E. A. (1986). Generalizing from laboratory to field: Ecological validity or abstraction of essential elements? In E. A. Locke (Ed.), Generalizing from laboratory to field settings. Lexington, MA: Lexington Books.

Maheswaran, D., \& Meyers-Levy, J. (1990). The influence of message framing and issue involvement. Journal of Marketing Research, 27, 361-367.

Maxwell, S. E. (2004). The persistence of underpowered studies in psychologica research: Causes, consequences, and remedies. Psychological Methods, 9, $147-163$.

Nicklin, J. M., Greenbaum, R. L., McNall, L. A., Folger, R., \& Williams, K. J. (2011). The importance of contextual variables when judging fairness: An examination of counterfactual thoughts and fairness theory. Organizational Behavior and Human Decision Processes, 114, 127-141.

Parducci, A. (1965). Category judgment: A range-frequency model. Psychological Review, 72, 407-418.

Plott, C. R., \& Zeiler, K. (2007). Exchange asymmetries incorrectly interpreted as evidence of endowment effect theory and prospect theory? The American Economic Review, 97, 1449-1466.

Preacher, K. J., \& Hayes, A. F. (2008). Contemporary approaches to assessing mediation in communication research. In A. F. Hayes, M. D. Slater, \& L. B. Snyder (Eds.), The Sage sourcebook of advanced data analysis methods for communication research (pp. 13-54). Thousand Oaks, CA: Sage Publications.

Roese, N. J. (1997). Counterfactual thinking. Psychological Bulletin, 121, 133-148.

Schmidt, U., Starmer, C., \& Sugden, R. (2008). Third-generation prospect theory. Journal of Risk and Uncertainty, 36, 203-223.

Shao, R., Rupp, D. E., Skarlicki, D. P., \& Jones, K. S. (2013). Employee justice across cultures: A meta-analytic review. Journal of Management, 39, 263-301.

Skitka, L., \& Mullen, E. (2002). The psychology of decision making: People in organizations. Personality and Social Psychology Bulletin, 28, 1419-1429.

Spencer, S., \& Rupp, D. E. (2009). Angry, guilty, and conflicted: Injustice toward coworkers heightens emotional labor through cognitive and emotional mechanisms. Journal of Applied Psychology, 94, 429-444.

Thaler, R. (1985). Mental accounting and consumer choice. Marketing Science, 3 $199-214$.

Thibaut, J., \& Walker, L. (1975). Procedural justice: A psychological analysis. Hillsdale, NJ: Erlbaum.

Thomson, J. J. (1985). The trolley problem. The Yale Law Journal, 94, 1395-1415.

Trepel, C., Fox, C. R., \& Poldrack, R. A. (2005). Prospect theory on the brain? Toward a cognitive neuroscience of decision under risk. Cognitive Brain Research, 23, $34-50$.

Tversky, A., \& Kahneman, D. (1981). The framing of decisions and the psychology of choice. Science, 211, 453-458. 